Pacific Journal of Mathematics

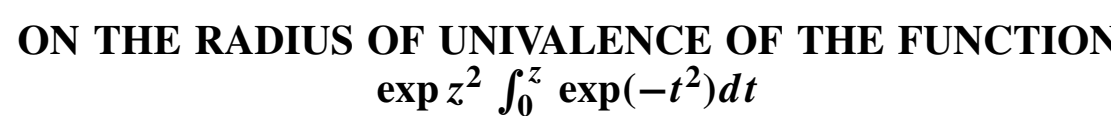




\section{ON THE RADIUS OF UNIVALENCE OF THE FUNCTION}

$$
\exp z^{2} \int_{0}^{z} \exp \left(-t^{2}\right) d t
$$

\section{ERWIN KREYSZIG AND JOHN TODD}

1. Introduction. We shall determine the radius of univalence $\rho_{u}$ of the function

$$
E(z)=e^{z^{2}} \int_{0}^{z} e^{-t^{2}} d t
$$

We shall write $E(z)=w=u(x, y)+i v(x, y)$. On the imaginary axis we have $u=0$ and $v$, regarded as a function of $y$, has a single maximum at the solution $y=\rho$ of

$$
2 y v(0, y)=1 \text {. }
$$

The value of $\rho$ to eight decimal places has been determined by Lash Miller and Gordon [1] and is

$$
\rho=0.92413887 \text {. }
$$

It is evident that $\rho_{u} \leqq \rho$. We shall prove the following theorem.

THEOREM. The number $\rho$ is the radius of univalence of $E(z)$.

Recently, the radius of univalence of the error function

$$
\operatorname{erf}(z)=\int_{0}^{z} e^{-t^{2}} d t
$$

was determined [2]. It is interesting to note that when proceeding from $\operatorname{erf}(z)$ to $E(z)$ we meet an entirely different situation. In the case of $\operatorname{erf}(z)$, points $z_{1}, z_{2}$ closest to the origin and such that $\operatorname{erf}\left(z_{1}\right)=\operatorname{erf}\left(z_{2}\right)$ are conjugate complex and lie far apart from each other. In the case of $E(z)$ points of that nature can be found in an arbitrarily small neigborhood of the point $z=i \rho$.

The actual situation is made clear by the diagram and tables given below. In Fig. 1 we show the curves $R=|E|=$ constant and $\gamma=$ $\arg E=$ constant in the square $0 \leqq x \leqq 1.5,0 \leqq y \leqq 1.5$ of the $z$-plane. The table shows the values of $E$ for $z$ on the curve $C$ (defined below). The values given were obtained by summing an adequate number of terms of the power series on the Datatron 205 at the California Institute of Technology ; some were checked by comparison with the tables of Karpov $[4,5]$ from which values of $E(z)$ can be obtained.

Received September 3, 1958. 
2. Idea of proof. Since

$$
E(z)=\sum_{n=0}^{\infty} \begin{gathered}
2^{n} \\
1.3 .5 \cdots(2 n+1)
\end{gathered} z^{z^{2 n+1}, \quad|z|<\infty,}
$$

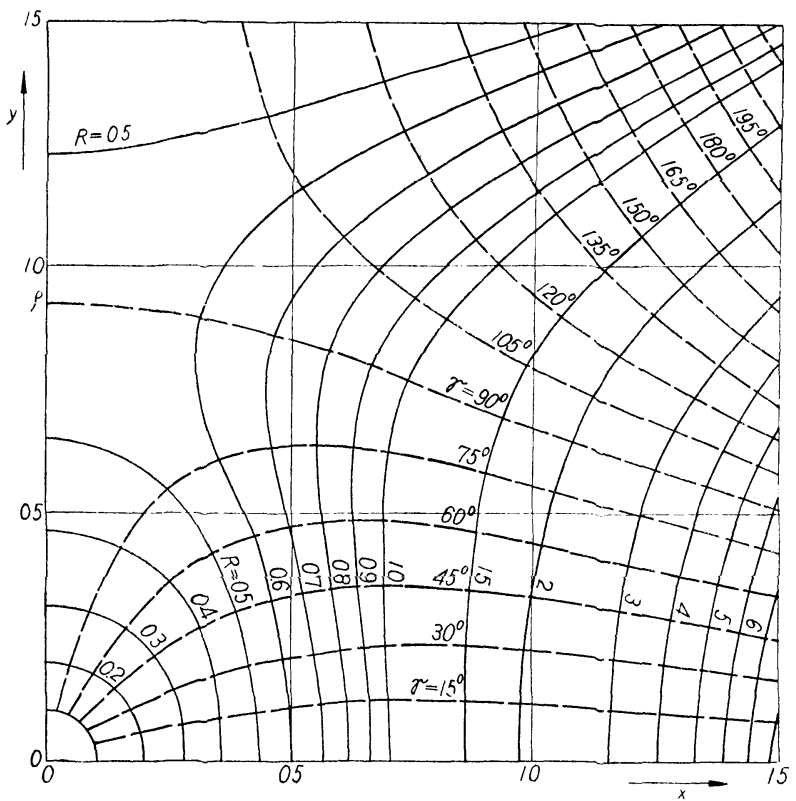

\begin{tabular}{|c|c|c|c|c|c|}
\hline$x$ & $E(x)$ & $\phi$ & $E\left(\rho e^{i \phi}\right)$ & $y$ & $E(i y)$ \\
\hline 0 & 0 & $0^{\circ}$ & 1.6837 & 0 & 0 \\
\hline 0.1 & 0.1007 & $10^{\circ}$ & $1.4957+0.6121 \mathrm{i}$ & 0.1 & $0.0993 \mathrm{i}$ \\
\hline 0.2 & 0.2054 & $20^{\circ}$ & $1.0573+0.9759 \mathrm{i}$ & 0.2 & $0.1948 \mathrm{i}$ \\
\hline 0.3 & 0.3187 & $30^{\circ}$ & $0.6079+1.0473 \mathrm{i}$ & 0.3 & $0.2826 \mathrm{i}$ \\
\hline 0.4 & 0.4455 & $40^{\circ}$ & $0.2919+0.9463 \mathrm{i}$ & 0.4 & $0.3599 \mathrm{i}$ \\
\hline 0.5 & 0.5923 & $50^{\circ}$ & $0.1189+0.8024 \mathrm{i}$ & 0.5 & $0.4244 \mathrm{i}$ \\
\hline 0.6 & 0.7671 & $60^{\circ}$ & $0.0401+0.6817 \mathrm{i}$ & 0.6 & $0.4748 \mathrm{i}$ \\
\hline 0.7 & 0.9805 & $70^{\circ}$ & $0.0099+0.6003 i$ & 0.7 & $0.5105 \mathrm{i}$ \\
\hline 0.8 & 1.2473 & $80^{\circ}$ & $0.0011+0.5553 \mathrm{i}$ & 0.8 & $0.5321 \mathrm{i}$ \\
\hline 0.9 & 1.5876 & $90^{\circ}$ & $0.5410 \mathrm{i}$ & 0.9 & $0.5407 \mathrm{i}$ \\
\hline
\end{tabular}

Fig. 1. Curves $R=|E|=$ const. and $\gamma=\arg E=$ const. in the $z$-plane.

we have $E(\bar{z})=\overline{E(z)}$ and $E(-z)=-E(z)$ and may restrict our consideration to the first quadrant $x \geqq 0, y \geqq 0$ in the $z$-plane.

In the subsequent section we shall prove the following lemma.

\section{LEMMA.}

$$
E\left(z_{1}\right) \neq E\left(z_{2}\right)
$$

for any two points on the boundary $C$ of the open sector $S$ of the circular disk $|z|<o$ in the first quadrant. 
From this it follows, since $E(z)$ is entire and thus regular in $S \cup C$ that $E(z)$ maps $S$ conformally and one-to-one onto the interior of the simple closed curve $C^{*}$ corresponding to $C$ in the $w$-plane [3, p. 121]. This establishes our theorem.

3. Proof of the lemma. Let $z=r e^{i \phi}$. The curve $C$ consists of the segment $S_{1}: \quad y=0,0<x<\rho$, the circular arc $K:|z|=\rho, 0<\phi<\pi / 2$, the segment $S_{2}: \quad x=0,0<y<\rho$.

and the three common end points of these three arcs.

(A) On $S_{1}, E(z)$ is real and increases steadily with $x$.

(B) On $S_{2}, E(z)$ is imaginary, and $v$ increases steadily with $y$.

(C) $v \neq 0$ on $K$.

(D) On $K,|E(z)|$ decreases steadily with increasing $\phi$.

(A) is obvious from (2.1), and (B) follows from the definition of $\rho$.

Proof of $(\mathrm{C})$. Integrating along segments parallel to the coordinate axes we have

$$
\begin{aligned}
v(x, y)= & e^{-y^{2}}\left[\cos 2 x y \int_{0}^{y} e^{\tau^{2}} \cos 2 x \tau d \tau\right. \\
& \left.+\sin 2 x y\left\{e^{x^{2}} \int_{0}^{x} e^{-t^{2}} d t+\int_{0}^{y} e^{\tau^{2}} \sin 2 x \tau d \tau\right\}\right] .
\end{aligned}
$$

In $\{x>0, y>0\} \cap\{|z| \leqq \rho\}$ we have $\cos 2 x y>0$, $\sin 2 x y>0$. Therefore $v>0$ on $K$.

Proof of (D). Integrating along a radius $\phi=$ constant from 0 to $\rho$ we have

$$
E(z)=e^{i \phi} \int_{0}^{\rho} e^{h(r, \phi)} d r
$$

where

$$
\begin{gathered}
h(r, \phi)=a(r, \phi)+i b(r, \phi), \\
a(r, \phi)=\left(\rho^{2}-r^{2}\right) \cos 2 \phi, b(r, \phi)=\left(\rho^{2}-r^{2}\right) \sin 2 \phi .
\end{gathered}
$$

Therefore

$$
|E|^{2}=\int_{0}^{\curvearrowright} e^{h} d r \int_{0}^{\rho} e^{\ddot{h}} d r .
$$

Differentiating with respect to $\phi$ and setting

$$
\begin{gathered}
h^{*}=a^{*}+i b^{*}, a^{*}=a\left(r^{*}, \phi\right), b^{*}=b\left(r^{*}, \phi\right), \\
f=\cos \left(b^{*}-b\right)-i \sin \left(b^{*}-b\right)
\end{gathered}
$$

we obtain 


$$
\begin{aligned}
\left(|E|^{2}\right)_{\phi} & =\int_{0}^{\rho} e^{h} h_{\phi} d r \int_{0}^{\rho} e^{\bar{h}} d r^{*}+\int_{0}^{\rho} e^{h^{*}} d r^{*} \int_{0}^{\rho} e^{\bar{h}} \overline{h_{\phi}} d r \\
& =\int_{0}^{\rho} \int_{0}^{\rho} e^{a+a^{*}}\left\{f h_{\phi}+\bar{f}_{\phi}\right\} d r d r^{*} .
\end{aligned}
$$

Now

$$
a_{\phi}=-2\left(\rho^{2}-r^{2}\right) \sin 2 \phi, b_{\phi}=2\left(\rho^{2}-r^{2}\right) \cos 2 \phi
$$

and therefore

$$
\begin{aligned}
f h_{\phi}+\overline{f h_{\phi}} & =2 \Re f h_{\phi}=2\left[\cos \left(b^{*}-b\right) a_{\phi}+\sin \left(b^{*}-b\right) b_{\phi}\right] \\
& =-4\left(\rho^{2}-r^{2}\right) \sin (\alpha(\phi))
\end{aligned}
$$

where

$$
\alpha(\phi)=2 \phi+b-b^{*}=\left(r^{* 2}-r^{2}\right) \sin 2 \phi+2 \phi .
$$

This yields

$$
\left(|E|^{2}\right)_{\phi}=-4 \int_{0}^{\rho} \int_{0}^{\rho} e^{a+a^{*}}\left(\rho^{2}-r^{2}\right) \sin (\alpha(\phi)) d r d r^{*} .
$$

Since from (1.2) we have $\left|r^{* 2}-r^{2}\right|<1$, we obtain

$$
\alpha^{\prime}(\phi)=2+2\left(r^{* 2}-r^{2}\right) \cos 2 \phi>0 .
$$

Hence $\alpha(\phi), 0 \leqq \phi \leqq \pi / 2$, has its maximum at $\phi=\pi / 2$. Therefore $0 \leqq \alpha(\phi)<\pi$ when $0 \leqq \phi<\pi / 2$ and $\sin (\alpha(\phi))>0$ when $0<\phi<\pi / 2$. This means that the integrand in (3.1) is positive in the region $0 \leqq r \leqq \rho$, $0 \leqq r^{*} \leqq \rho$ for all $\phi$ in the interval $0<\phi<\pi / 2$. Thus $\left(|E|^{2}\right)_{\phi}<0$ when $0<\phi<\pi / 2$. This proves (D).

We note that (D) remains true if $K$ is replaced by quadrants of circles of radii somewhat larger than $\rho$; this, however, is of no interest here.

For $z_{1} \in K, z_{2} \in S_{2}$, or $z_{1} \in K, z_{2} \in K$, equation (2.2) holds, as follows from (D). For $z_{1} \in K, z_{2} \in S_{1}$ the same is true because of (C). In the other cases, $z_{1} \in S_{1}, z_{2} \in S_{1}$, etc., the validity of (2.2) is obvious. This proves the lemma.

\section{REFERENCES}

1. W. Lash Miller and A. R. Gordon, Numerical evaluation of infinite series and inieg. rals which arise in certain problems of linear heat flow, electrochemical diffusion etc., J. Phys. Chem. 35 (1931), 2785-2884. We are indebted to Dr. Walter Gautschi for this reference; Dr. Gautschi has recomputed the value of $\rho$ and communicated the following $10 \mathrm{D}$ value

$$
\rho=0.9241388730 \text {. }
$$

2. Erwin Kreyszig and John Todd, The radius of univalence of erf $z$, Bull. Amer. Math. Soc. 64 (1958), 363-364, and Numerische Mathematik 1 (1959) to appear. 
3. J. E. Littlewood, Lectures on the Theory of Functions, Oxford, 1944.

4. K. A. Karpov, Taklicy funkcii $w(z)=e^{-z^{2}} \int_{0}^{z} e^{x^{2}} d x v$ kompleksnoi oklasti, Moscow, 1956.

5. K. A. Karpov Taklicy funkcii $F(z)=\int_{0}^{z} e^{x^{2}} d x v$ kompleksnoi oklasti, Moscow, 1958.

Ohio State University

COLumbus, OHIO

CALIFornia Institute of TeChNOLOGY

PASADENA, CALIFORNIA 



\section{PACIFIC JOURNAL OF MATHEMATICS}

\section{EDITORS}

\section{David Gilbarg}

Stanford University

Stanford, California

R. A. Beaumont

University of Washington

Seattle 5 , Washington
A. L. Whiteman

University of Southern California

Los Angeles 7, California

L. J. PAIGE

University of California

Los Angeles 24, California

\section{ASSOCIATE EDITORS}
E. F. BECKENBACH
C. E. BURGESS
E. HEWITT
A. HORN

\author{
V. GANAPATHY IYER \\ R. D. JAMES \\ M. S. KNEBELMAN \\ L. NACHBIN
}
I. NIVEN
E. G. STRAUS
T. G. OSTROM
H. L. ROYDEN
G. SZEKERES
M. M. SCHIFFER
F. WOLF
K. YOSIDA

\section{SUPPORTING INSTITUTIONS}

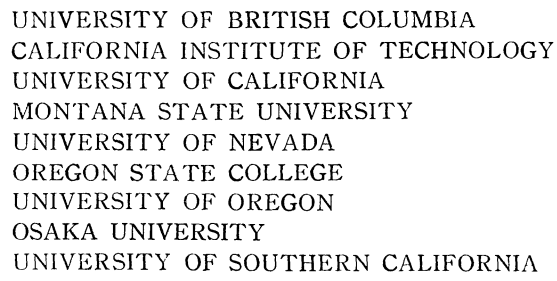

UNIVERSITY OF BRITISH COLUMBIA CALIFORNIA INSTITUTE OF TECHNOLOGY UNIVERSITY OF CALIFORNIA MONTANA STATE UNIVERSITY UNIVERSITY OF NEVADA OREGON STATE COLLEGE UNIVERSITY OF OREGON OSAKA UNIVERSITY UNIVERSITY OF SOUTHERN CALIFORNIA

STANFORD UNIVERSITY

UNIVERSITY OF TOKYO

UNIVERSITY OF UTAH

WASHINGTON STATE COLLEGE

UNIVERSITY OF WASHINGTON

AMERICAN MATHEMATICAL SOCIETY CALIFORNIA RESEARCH CORPORATION HUGHES AIRCRAFT COMPANY SPACE TECHNOLOGY LABORATORIES

Printed in Japan by Kokusai Bunken Insatsusha (International Academic Printing Co., Ltd.), Tokyo, Japan 


\section{Pacific Journal of Mathematics}

\section{Vol. 9, No. 1 \\ May, 1959}

Julius Rubin Blum and Murray Rosenblatt, On the structure of infinitely

divisible distributions . ............................. 1

Robert Geroge Buschman, Asymptotic expressions for

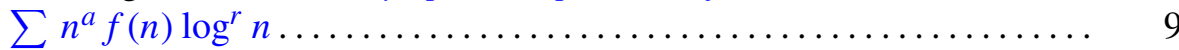

Eckford Cohen, A class of residue systems $(\bmod r)$ and related arithmetical

functions. I. A generalization of Möbius inversion .............. 13

Paul F. Conrad, Non-abelian ordered groups ................... 25

Richard Henry Crowell, On the van Kampen theorem............... 43

Irving Leonard Glicksberg, Convolution semigroups of measures ........ 51

Seymour Goldberg, Linear operators and their conjugates ............ 69

Olof Hanner, Mean play of sums of positional games .............. 81

Erhard Heinz, On one-to-one harmonic mappings ................ 101

John Rolfe Isbell, On finite-dimensional uniform spaces . . ........... 107

Erwin Kreyszig and John Todd, On the radius of univalence of the function

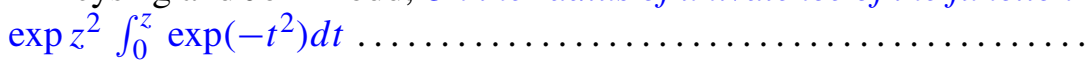

Roger Conant Lyndon, An interpolation theorem in the predicate

calculus......................................... 129

Roger Conant Lyndon, Properties preserved under homomorphism ........ 143

Roger Conant Lyndon, Properties preserved in subdirect products ....... 155

Robert Osserman, A lemma on analytic curves ................ 165

R. S. Phillips, On a theorem due to Sz.-Nagy..................... 169

Richard Scott Pierce, A generalization of atomic Boolean algebras ....... 175

J. B. Roberts, Analytic continuation of meromorphic functions in valued fields................................. 183

Walter Rudin, Idempotent measures on Abelian groups ................ 195

M. Schiffer, Fredholm eigen values of multiply-connected domains ........ 211

V. N. Singh, A note on the computation of Alder's polynomials ......... 271

Maurice Sion, On integration of 1-forms ...................... 277

Elbert A. Walker, Subdirect sums and infinite Abelian groups........... 287

John W. Woll, Homogeneous stochastic processes . .................. 293 